Turkish Journal of Unmanned Aerial Vehicles

Türkiye İnsansız Hava Araçları Dergisi

https://dergipark.org.tr/tr/pub/tiha

e-ISSN 2687-6094

\title{
SenseFly eBeeX İHA İle Üretilen Ortofotonun Konum Doğruluğunun İncelenmesi
}

\author{
Alper AKAR*1@, ${ }^{*}$ zlem AKAR ${ }^{1}$, Halim Ferit BAYATA2 ${ }^{\circledR}$ \\ ${ }^{1}$ Erzincan Binali Yıldırım Üniversitesi, Meslek Yüksek Okulu, Mimarlık ve Şehir Planlama Bölümü, Harita ve Kadastro Programı, \\ Erzincan, Türkiye \\ ${ }^{2}$ Erzincan Binali Yıldırım Üniversitesi, Mühendislik-Mimarlık Fakültesi, İnşaat Mühendisliği, Erzincan, Türkiye
}

\author{
Anahtar Kelimeler \\ İHA, \\ Ortofoto, \\ Fotogrametri, \\ GZK.
}

\begin{abstract}
ÖZ
Son yıllarda insansız hava araçlarının (IHHA), hem yüksek konumsal çözünürlükte hem de çok bantlı görüntü sağlaması sayesinde bu araçların kullanımı giderek yaygınlaşmaktadır. Klasik fotogrametrik haritalama yöntemlerine göre İHA' ların haritalama maliyetinin düşük olması, istenilen zaman ve sıklıkta görüntü elde edilebilmesi, kullanıcılar için bu araçların daha çok tercih edilmesini sağlamaktadır. Bunun yanında günümüzde İHA' lara gerçek zamanlı kinematik (GZK) konumlandırma sistemleri de takılabilmekte ve bu sayede hassas konum bilgisine sahip görüntüler elde edilebilmektedir. $\mathrm{Bu}$ da İHA ile üretilen fotogrametrik ürünlerin doğruluğunun, yersel ölçme yöntemleri ile elde edilen sonuçlara daha yakın olmasını mümkün kılmaktadır. Yapılan çalıșmada Erzincan Binali Yıldırım Üniversitesi Yalnızbağ Yerleşkesi için SenseFly eBeeX İHA ile üretilen ortofotonun konum doğruluğunun araştırılması amaçlanmıştır. Üretilen ortofotonun konum doğruluğu için çalışma alanına rasgele ve homojen olarak dağılmış 100 nokta, görüntü üzerinde işaretlenmiştir. Bu noktaların hem hâlihazır harita üzerinden hem de ortofoto üzerinden $Y$ ve X koordinatları alınmış ve koordinat farklarından ortofotonun konum doğruluğu hesaplanmıştır. Sonuç olarak üretilen ortofotonun konum doğruluğu $Y$ ve $X$ yönlerinde $m_{y}= \pm 1.0 \mathrm{~cm}, m_{x}= \pm 0.8 \mathrm{~cm}$, yatayda ise $m_{k}$ $= \pm 1.3 \mathrm{~cm}$ olarak hesaplanmıştır. Bu sonuç bize üretilen ortofotonun birçok mühendislik projesinde altlık olarak kullanılabileceğini göstermiștir.
\end{abstract}

\section{Investigation of Position Accuracy of Orthophoto Produced by SenseFly eBeeX UAV}

\author{
Keywords \\ UAV, \\ Orthophoto, \\ Photogrammetry, \\ Real-Time Kinematic.
}

\begin{abstract}
In recent years, the use of unmanned aerial vehicles (UAV) has become increasingly widespread, thanks to providing both high spatial resolution and multi-band imagery. Compared to classical photogrammetric mapping methods, the low cost of mapping UAVs and the ability to obtain images at the desired time and frequency make these tools more preferred for users. In addition, real-time kinematics (RTK) positioning systems can be installed on UAVs, and images with precise location information can be obtained by this means. This makes it possible for the accuracy of photogrammetric products produced by UAVs to be closer to the results obtained by terrestrial measurement methods. In this study, orthophoto of Erzincan Binali Yıldırım University Yalnızbă Campus was produced with SenseFly eBeeX UAV. In this study, it was aimed to investigate the position accuracy of the orthophoto produced by SenseFly eBeeX UAV for Erzincan Binali Yıldırım University Yalnızbağ Campus. For the location accuracy of the produced orthophoto, 100 points randomly and homogeneously distributed over the study area were marked on the image. The $Y$ and $X$ coordinates of these points were taken both on the current map and the orthophoto, and the position accuracy of the orthophoto was calculated from the coordinate differences. As a result, the position accuracy of the produced orthophoto was calculated as $m_{y}= \pm 1.0 \mathrm{~cm}, m_{x}= \pm 0.8 \mathrm{~cm}$ in the $Y$ and $X$ directions, and $m_{k}= \pm 1.3 \mathrm{~cm}$ in the horizontal. This result has shown us that the orthophoto produced with the SenseFly eBeeX UAV can be used as a base in many engineering projects.
\end{abstract}




\section{GİRiş}

Son ylllarda, yüksek çözünürlükte ve çok bantlı görüntüler kullanılarak yapılan akademik çalışmalar ve üretilen projeler oldukça yaygınlaşmıştır. İHA' ların üretiminde yaşanan teknolojik gelişmelerin her geçen gün bu ihtiyacı karşılamaya başlamasının da etkisiyle, IHA' lara olan talep giderek artmaktadır. Günümüzde İHA' lar ormancılık, madencilik, haritacılık, tarım, fotogrametrik kadastro uygulamaları gibi birçok alanda kullanılmaktadır (Shin vd., 2019, Werner vd., 2019, Marques Junior vd., 2020, Ulvi, 2018, Yakar vd., 2014; Manyoky, vd., 2011; Alptekin vd., 2019).

İHA' lar ile yapılan fotogrametrik çalışmalar, klasik hava fotogrametrisi ile yapılan çalışmalarla karşılaştırıldığında yüksek mekânsal ve zamansal çözünürlük olanakları sağladığı için kullanımı da giderek yaygınlaşmaktadır (Orhan vd., 2020; Avcı \& Maraş, 2021). İHA' lar hava şartları müsait olduğu sürece herhangi bir çalışma alanına ait yüksek çözünürlükte görüntü almayı sağlayarak, uydu sistemleri ve klasik ölçme yöntemlerine nazaran maliyet ve zamandan kazanç sağlamaktadır. İHA' lar, uzaktan algılama ve uydu platformları ile karşılaştırıldıklarında, daha güncel haritalar üretilmesine imkân sağlamaktadır (Ö̈zcan, 2017; Erene \& Yakar, 2012). Günümüzde İHA' larda gerçek zamanlı kinematik (GZK) konum üretebilen sistemlerin de olması, görüntülere daha hassas konum bilgisi tanımlanabilmesini sağlamaktadır. Bu sayede İHA kullanılarak üretilen fotogrametrik ürünlerin doğruluğu, yersel ölçme yöntemleri ile elde edilen doğruluk değerlerine yaklaşmıştır (Ulvi \& Yakar, 2010; Remondino vd. 2011, Öztürk vd, 2017; Yılmaz vd., 2018).

Son yıllarda birçok kurum ve kuruluş tarafindan CORS (Continuously Operating Reference Stations) olarak bilinen sabit GNSS referans istasyonu ağları kurulmuştur. $\mathrm{Bu}$ ağların kullanımının yaygınlaşması kullanıcılara anlık ve hassas konum elde etme gibi önemli faydalar sağlamaktadır. CORS sisteminde, veri aktarımı ve iletișim gerçek zamanlı hizmet verecek șekilde dizayn edilmiştir (Öcalan, 2015; Yakar vd., 2005; 2010). Türkiye'de CORS sistemi TUSAGA-Aktif ismiyle kurulmuş ve kullanıcılarına ağ-GZK mantığı ile hizmet vermektedir.

\section{YÖNTEM}

Çalışma alanına ait resimlerin çekimi öncesinde eMotion 3.2 programı kullanılarak çekim öncesi planlama işlemi gerçekleștirilmiştir. Planlamada uçağın kalkış ve iniş yerlerinin seçimi, enine ve boyuna bindirme oranı, uçuş yüksekliği, çözünürlük bilgileri ve uçuş rota bilgileri yer almaktadır. Planlama sonrasında SenseFly eBeeX İHA ile resim çekim işlemi yapılarak arazi çalışması tamamlanmıştır. Çekim işleminin tamamlanmasının ardından resimler bilgisayara aktarılmıștır. PIX4Dmapper programı ile aktarılan resimler değerlendirilerek ortofoto üretilmiştir. Kampüs alanına ait hâlihazır harita üzerinden kampüs alanına homojen olarak dağılmış 100 adet nokta rasgele seçilerek noktaların konum bilgileri alınmıștır. Daha sonra ortofoto Arcgis programında açlarak seçilen referans noktalarının koordinatları ortofoto üzerinden de alınarak koordinatlar arasındaki fark değerleri belirlenmiștir. Son olarak bu fark değerleri kullanılarak ortofotonun konum hassasiyeti hesaplanmıştır.

\section{UYGULAMA}

\section{1. Çalışma Alanı}

Çalışma alanı olarak Erzincan Binali Yıldırım Üniversitesi Yalnızbağ Yerleşkesi seçilmiştir. Yerleşke Erzincan il merkezi sınırları içerisinde yer alıp il merkezine yaklaşık $13 \mathrm{~km}$ uzaklıktadır. Çalışma alanı aşağıdaki şekilde gösterilmiştir (Şekil 1).

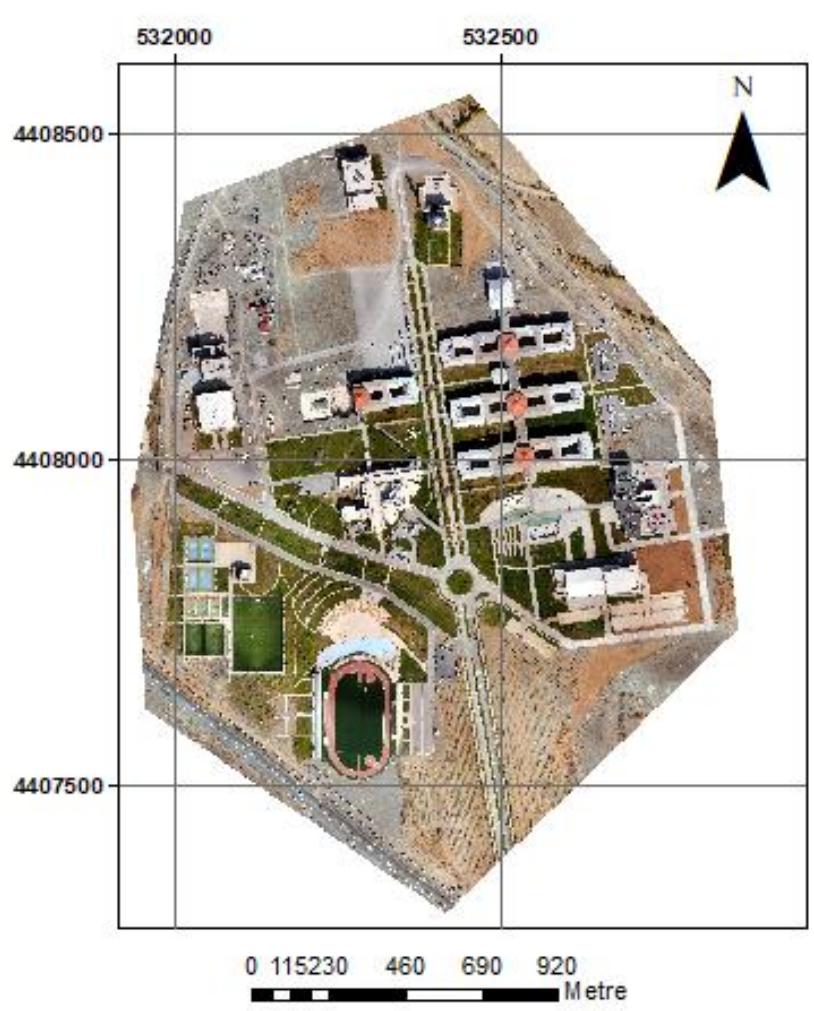

Şekil 1. Çalışma alanı

\subsection{Kullanılan Veri ve Özellikleri}

Çalışmada SenseFly eBeeX İHA kullanılmıştır. SenseFly eBeeX İHA $116 \mathrm{~cm}$ kanat açıklı̆̆ına sahip $1.7 \mathrm{~kg}$ ağırlığındadır. İHA, bataryasıyla tek uçuşta 500 ha alanı ölçebilmektedir. GZK/HNK (hassas nokta konumlama) seçeneği ile yüksek konumsal doğruluk elde edilebilmektedir. İHA 40 ile $110 \mathrm{~km}$ aralığında hızla uçabilmekte, $12.8 \mathrm{~m} / \mathrm{s}$ ye kadar rüzgârda uçuşunu gerçekleştirebilmektedir.

Resim çekim işlemine başlamadan önce eMotion programında uçuş planlaması yapılır. Planlamada iniş ve kalkış noktaları, çalışma alanının sınırları, enine ve boyuna bindirme oranları ve uçuş yüksekliği belirlenir. Seçilen bilgilere göre program çekeceği fotoğraf sayısını ve takip edeceği güzergâhı belirler. Güzergâh takibi İHA üzerindeki GNSS alıcısı sayesinde olmaktadır. Çalışma alanına ait resimler senseFly S.O.D.A. kamera ile çekilmiştir. Kamera 20 mega piksel çözünürlükte olup $10.6 \mathrm{~mm}$ odak uzaklığına sahiptir. 


\subsection{Ortofoto Üretimi ve Doğruluk Analizi}

Çalışma alanı toplam 116.5 hektar alanı kapsamaktadır. İlk önce eMotion programında uçuş öncesi planlama işlemi gerçekleștirilmiştir. Çekim alanı sınırları belirlendikten sonra çekimin $220 \mathrm{~m}$ yükseklikten, $\% 70$ enine ve $\% 70$ boyuna bindirme oranı ile yapılması planlanmıștır.

Yapılan planlama İHA' ya eMotion programı üzerinden gönderilmiş ve TUSAGA-Aktif bağlantısı da sağlandıktan sonra uçuş işlemine geçilmiştir. Uçuş süresi 35 dakikada tamamlanmış olup toplamda 281 adet renkli hava fotoğrafının çekim işlemi gerçekleştirilmiştir.

Uçuş işlemi sonrasında veriler bilgisayara aktarılarak resimlerin değerlendirilmesi işlemine geçilmiştir. Resimler PIX4Dmapper programında değerlendirilerek ortofoto üretilmiștir. Değerlendirme sonrası yer örnekleme aralığı (YÖA/GSD) $5.61 \mathrm{~cm}$ olarak elde edilmiştir. Ortofoto üretildikten sonra kampüs alanına ait hâlihazır harita üzerinden homojen olarak dağılmış 100 adet nokta rasgele belirlenmiștir. Bu noktaların $\mathrm{Y}$ ve $\mathrm{X}$ değerleri kesin değer kabul edilmiştir. Daha sonra üretilen ortofoto ArcGIS programında açılarak koordinat okumaları ortofoto üzerinden de yapılmıştır. Hâlihazır harita üzerinden alınan noktalar referans noktası, ortofoto üzerinden alınan noktalarda test noktası olarak kabul edilerek referans ve test noktalarının koordinatlarının farkları hesaplanmıștır. $\mathrm{Bu}$ farklar kullanılarak konum hataları $\mathrm{Y}$ ve $\mathrm{X}$ yönlerinde sırasıyla $m_{y}, m_{x}$ ve yataydaki konum hatası $m_{k}$ hesaplanmıștır (Eşitlik 1).

$$
m_{y}=\sqrt{\frac{[\Delta y]^{2}}{n}} m_{x}=\sqrt{\frac{[\Delta x]^{2}}{n}} m_{k}=\sqrt{m_{y}^{2}+m_{x}^{2}}
$$

Aşağıdaki şekilde koordinat okuması yapılan noktalarının çalışma alanına dağılımı gösterilmiştir (Şekil 2).

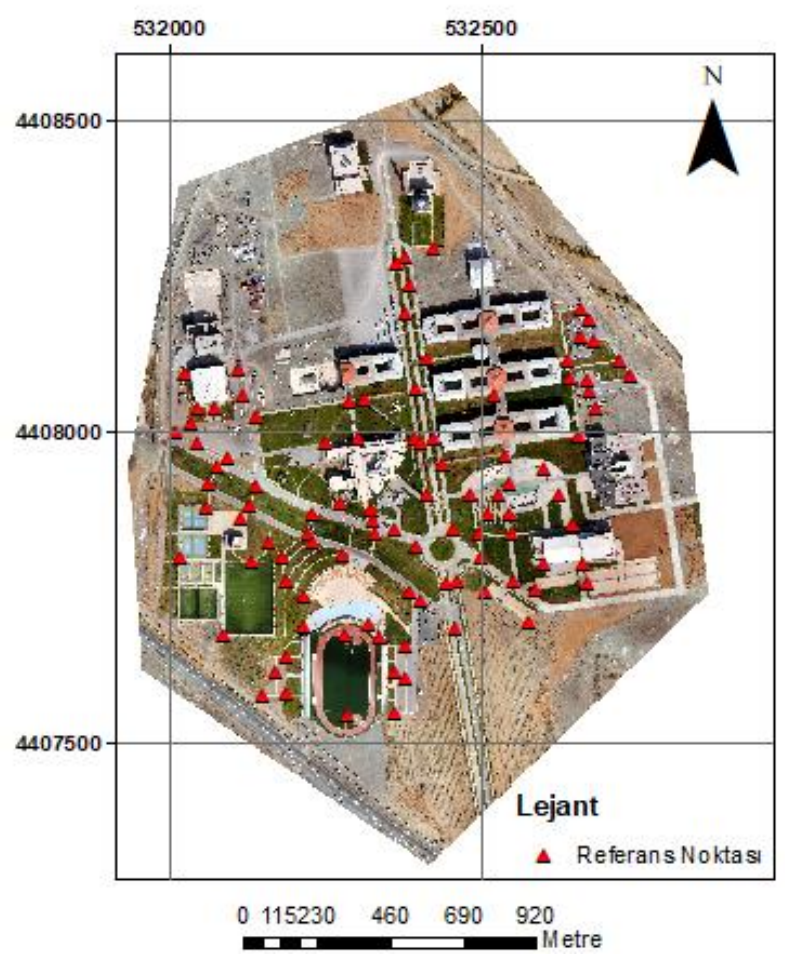

Şekil 2. Noktaların çalışma alanına dağılımı

\section{BULGULAR}

SenseFly eBeeX İHA ile Erzincan Binali Ylldırım Üniversitesi Yalnızbağ Yerleşkesinin fotoğrafları çekilmiş ve ortofotosu üretilmiştir. Yerleşkenin hâlihazır haritası üzerinden seçilen noktaların koordinatları ile üretilen ortofotonun üzerinden seçilen aynı noktaların koordinat farkları kullanılarak üretilen ortofotonun konum hassasiyeti değerlendirilmiştir. $\mathrm{Bu}$ farklar kullanılarak hesaplanan konum hataları $\mathrm{Y}$ ve $\mathrm{X}$ yönlerinde sırasıyla $\mathrm{m}_{\mathrm{Y}}= \pm 1.0 \mathrm{~cm}$ ve $\mathrm{m}_{\mathrm{y}}= \pm 0.8 \mathrm{~cm}$ olarak belirlenmiş̦tir. Yataydaki konum hatası $\mathrm{m}_{\mathrm{k}}= \pm 1.3 \mathrm{~cm}$ olarak hesaplanmıştır.

\section{SONUÇLAR}

Bu çalışmada SenseFly eBeeX İHA kullanılarak üretilen ortofotonun konum hassasiyeti irdelenmiştir. Yapılan hesaplamalar sonrasinda üretilen ortofotonun konum doğruluğu $\mathrm{Y}$ ve $\mathrm{X}$ yönlerinde sırası ile my $= \pm 1.0$ $\mathrm{cm}, \mathrm{mx}= \pm 0.8 \mathrm{~cm}$, yatayda ise $\mathrm{mk}= \pm 1.3 \mathrm{~cm}$ olarak hesaplanmıștır. Elde edilen değerler harita üretiminde referans olarak kabul edilen Büyük Ölçekli Harita ve Harita Bilgileri Üretim Yönetmeliği' nde belirtilen tecviz sınırları içerisinde kalmaktadır. Yönetmeliğe göre bu değerler 1/1000 ölçekli ortofoto harita üretimi için yeterlidir. $\mathrm{Bu}$ nedenle üretilen ortofotonun birçok mühendislik projesinde rahatlıkla kullanılabileceği söylenebilir. Düşük maliyetli, hızl, vektör veri üretilmesine imkân sağlaması yanında yüksek çözünürlükte güncel arazi görüntüsünü de sağlaması sayesinde insansız hava araçları, küçük alanların haritalanması çalışmalarında tercih edilebilir. Daha sonraki çalışmalarda yataydaki konum doğruluğunun yanı sıra düşeydeki konumsal doğruluk da incelenecektir.

\section{Bilgilendirme/Teșekkür}

Ortofotonun üretilmesinde kullanılan hava fotoğraflarını tarafımıza sağlayan Paksoy Teknik Hizmetler Tic. Ltd. Şti. ye teşekkür ederiz.

\section{Yazarların Katkısı}

Yazarlardan Alper AKAR arazi çalış̧malarına, doğruluk analizine ve makale yazımına, Özlem AKAR ortofoto haritanın üretimine, doğruluk analizine ve makalenin yazımına, Halim Ferit BAYATA' da arazi çalışmalarına ve makalenin yazımına katkı sağlamışlardır.

\section{Çıkar Çatışmasıs Beyanı}

Yazarlar arasında herhangi bir çıkar çatışması bulunmamaktadır.

\section{Araştırma ve Yayın Etiği Beyanı}

Yapılan çalışmada araştırma ve yayın etiğine uyulmuştur. 


\section{KAYNAKÇA}

Alptekin A, Çelik M Ö, Doğan Y \& Yakar M (2019). Mapping of a Rockfall Site With an Unmanned Aerial Vehicle. Mersin Photogrammetry Journal, 1(1), 1216.

Avcı H \& Maraş E E (2021). Dağlık, Engebeli Arazilerde İnsansız Hava Araçları İle Fotogrametrik Veri Üretiminde Doğruluk Araştırması: Yusufeli Barajı Örneği. Afyon Kocatepe University Journal of Science and Engineering, 21(2), 382-398. https://doi.org/10.35414/akufemubid.820829

Erener A \& Yakar M (2012). Monitoring Coastline Change Using Remote Sensing and GIS Technologies. Lecture Notes Inform Technol, 30, 310-314.

Manyoky M, Theiler P, Steudler D \& Eisenbeiss H (2011). Unmanned aerial vehicle in cadastral applications. International Archives of the Photogrammetry, Remote Sensing and Spatial Information Sciences, XXXVIII(1/C22), https://doi.org/10.3929/ethz-b-000041977

Marques Junior A, Maria De Castro D, Guimarães T T, Inocencio L C, Veronez M R, Mauad F F \& Gonzaga Jr L (2020). Statistical assessment of cartographic product from photogrammetry and fixed-wing UAV acquisition. European Journal of Remote Sensing, 53(1), 27-39.

Öcalan T (2015). GNSS Ağlarında GPS Hassas Nokta Konumlama (GPS-PPP) Tekniği Yaklaşımlı Çözümler. Doktora tezi, Yıldız Teknik Üniversitesi, Fen Bilimleri Enstitüsü, İstanbul, 177.

Özcan O (2017). İnsansız Hava Aracı (İHA) ile Farklı Yüksekliklerden Üretilen Sayısal Yüzey Modellerinin (SYM) Doğruluk Analizi. Mühendislik ve Yer Bilimleri Dergisi, 2(1), 1-7.

Öztürk O, Bilgilioğlu B B, Çelik M F, Bilgilioğlu S S \& Raşit U (2017). İnsanız Hava Aracı (İHA) Görüntüleri İle Ortofoto Üretiminde Yükseklik ve Kamera Açısının Doğruluğa Etkisinin Araştırılması. Geomatik Dergisi, 2(3), 135-142.

Remondino F, Barazzetti L, Nex F, Scaioni M \& Sarazzi D (2011). UAV photogrammetry for mapping and 3d modeling-current status and future perspectives. International archives of the photogrammetry, remote sensing and spatial information sciences, 38(1/C22), 25-31. doi:10.5194/isprsarchivesXXXVIII-5191-C5122-5125- 2011.
Shin J, Seo W, Kim T, Park J \& Woo C (2019). Using UAV Multispectral Images for Classification of Forest Burn Severity - A Case Study of the 2019 Gangneung Forest Fire. Forests, 10(11), 1025. https://doi.org/10.3390/f10111025

Orhan 0, Yakar M \& Ekercin S (2020). An application on sinkhole susceptibility mapping by integrating remote sensing and geographic information systems. Arabian Journal of Geosciences, 13(17), 117.

Ulvi A \& Yakar M (2010). An experimental study on preparing photogrammetric rolove plans of antique theatres. International Journal of Physical Sciences, 5(7), 1086-1092.

Ulvi A (2018). Analysis of the Utility Of The Unmanned Aerial Vehiele (UAV) in Volume Caleulation by Using Photogrammetrie Teehniques. International Journal of Engineering and Geoseienees, 3(2), 43-49. https://doi.org/10.26833/ijeg.377080

Werner T, Bebbington A \& Gregory G (2019). Assessing impacts of mining: Recent contributions from GIS and remote sensing. The Extractive Industries Society, 6(3), 993-1012. https://doi.org/10.1016/j.exis.2019.06.01

Yakar M, Yıldız F \& Yılmaz H M (2005). Tarihi ve Kültürel Miraslarin Belgelenmesinde Jeodezi Fotogrametri Mühendislerinin Rolü. TMMOB Harita ve Kadastro Mühendisleri Odası, 10.

Yakar M, Yılmaz H M \& Mutluoglu O (2014). Performance of photogrammetric and terrestrial laser scanning methods in volume computing of excavation and filling areas. Arabian Journal for Science and Engineering, 39, 387-394. https://doi.org/10.1007/s13369-013-0853-1

Yakar M, Yılmaz H M \& Mutluoğlu Ö (2010). Comparative evaluation of excavation volume by TLS and total topographic station based methods. Lasers in Eng, $19,331-345$.

Yılmaz H M, Mutluoğlu Ö, Ulvi A, Yaman A \& Bilgilioğlu S S (2018). İnsansız Hava Aracı ile Ortofoto Üretimi ve Aksaray Kampüsü Örneği. Geomatik Dergisi, 3(2), 129-136. 